\title{
Defect Closure With Buccal Fat Pad After Enucleation of Maxillary Dentigerous Cyst.
}

\author{
Kiran Kumar Sadula ${ }^{1}$, Pavan Kumar B², Brahmaji Rao J ${ }^{3}$, Haripriya Chari ${ }^{4}$
}

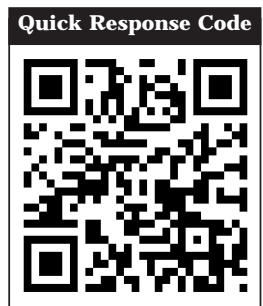

doi: $10.5866 / 2017.9 .10065$

1Post Graduate Student

2Prof \& HOD

${ }^{3}$ Professor

${ }^{4}$ Senior Lecturer

Department of Oral \& Maxillofacial Surgery,

Kamineni Institute of Dental Sciences,

Narketpally,Nalgonda, Telangana State.

\section{Article Info:}

Received: J anuary 8, 2017

Review Completed: February 7, 2017

Accepted: March 6, 2017

Available Online: March, 2017 (www.nacd.in)

(c) NAD, 2017 - All rights reserved

\section{Email for correspondence:}

sadula.kk@gmail.com

\begin{abstract}
:
Dentigerous cyst involving maxillary sinus with ectopic third molar has a low incidence with few cases has been reported and discussed in literature. Usually these are asymptomatic unless they are infected. Early surgical intervention and initial enucleation with tooth removal is al ways a treatment of choice. Here we present a case with dentigerous cyst involving left maxillary antrum with impacted third molar which was treated under general anaesthesia by approaching lateral window technique and closure done with buccal fat pad. The patient was asymptomatic for 2 years without any complications.
\end{abstract}

\section{INTRODUCTION}

Tooth development results from a complicated multistep interaction between the oral epithelium and the underlying mesenchymal tissue. A series of complex tissue interactions result in the formation of mature teeth. Abnormal tissue interactions during tooth development may potentially result in ectopic tooth development and eruption. ${ }^{1,2}$ The dentigerous cyst is a developmental odontogenic cyst which originates through alternations of the reduced enamel epithelium in an unerupted tooth, after the
Key words: Buccal fat pad, dentigerous cyst, maxillary sinus, ectopic tooth, third molar 
cyst involving left maxillary antrum with impacted third molar which was treated under general anaesthesia by approaching lateral window technique and closure done with buccal fat pad.

\section{CASE REPORT}

A 27 years old female patient reported with a complaint of discomfort and heaviness in left maxillary tooth region since 6 moths. History revealed that she has used medication for the same but symptoms didn't resolved. Extraorally, no inflammatory changes are seen on left maxillary region Intraoral examination showed missing left upper third molar and partially erupted bilateral lower third molars. No obliteration of buccal vestibule or no signs of swelling on palatal side.Panaromic radiograph showed third molar in upper left maxillary sinus (Figure 1 ). On CT examination axial, coronal and sagittal CT images showing impacted third molar in the posterior aspect of left maxillary sinus (Figure 2).

After performing routine surgical profile screening cyst enucleation along with defect closure using buccal fat pad is planned under general anaesthesia. A full thickness mucoperiosteal flap reflected from left maxillary second premolar to second molar. A $2 \mathrm{~cm}$ window was created in the lateral wall of maxilla and necrotic mass was curetted out. Along with the impacted third molar cystic lining was removed (Figure 3 ) and sent for histopathological examination. After enucleation buccal fat pad was teasedout carefully from same incision extending posteriorly and brought in to the surgical defect with the help of artery forceps (F igure 4). Care must be taken not to damage the buccal fat pad and its blood supply. Buccal fat padsecured in position with the help of $4-0$ vicryl then mucoperiosteal flap is replaced to its original position to prevent any loss of buccal vestibule (Figure 5).

Post operatively healing was uneventful without any complications and patient has no complain of discomfort or heaviness even after a follow-up period of 2 years. Panaromic radiograph shows good bone healing at the operated site.

\section{DISCUSSION}

Eruption of teeth into regions other than the oral cavity is rare, although there have been reports of teeth in the nasal cavity, mandibular condyle, coronoid process, and palate., ${ }^{2}$ One of the sites for an ectopic tooth in a nondental location is the maxillary sinus. ${ }^{2,8}$ They usually present with local sino-nasal symptoms attributed to recurrent or chronic sinusitis. The diagnosis and treatment plan of this condition can be made radiographically by OPG along with CT scans taken in all sections. ${ }^{1}$

Dentigerous cyst is the most common of all follicular cysts, more common in males, occurring in the second or third decade of life. About $70 \%$ of dentigerous cysts occur in the mandible and $30 \%$ in the maxilla. ${ }^{9} \mathrm{f}$ infected, the treatment of choice is complete enucleation of the lesion intraorally with removal of the associated tooth. It is also important to completely remove all diseased antral tissues and thoroughly assess all resected soft tissue histol ogically with a follow-up for a period of 1 year. ${ }^{10}$ Pedicled buccal fat pad flaps have been recommended for the closure of fistulas and in various areas; the use of pedicled buccal fat pad flaps has also been employed in the resolution of unsuccessful surgical cases in which lesions have devel oped. Among the advantages of this technique are the low morbidity rate, maintenance of the vestibular sulcus depth, the low incidence of failure, and the good flap vascularization. ${ }^{11}$

The standard treatment for a dentigerous cyst of maxilla is enucleation and extraction of the associated tooth via a Caldwell Luc procedure under local or general anesthesia. In large cysts, an initial marsupialization to diminish the size of the osseous defect, followed by enucleation and tooth extraction, has been followed. The major disadvantage of marsupialization is recurrence or persistence of the Iesion along with the residual cystic lining. Endoscopic approach for management of dentigerous cyst of maxilla is also described in the literature. This method is associated with lesser operative as well as postoperative morbidity. ${ }^{14}$ Dentigerous cyst of maxilla may cause pathological jaw fracture if large enough, may transform into ameloblastoma, and has the potential of developing into squamous cell carcinoma and mucoepidermoid carcinoma if there is chronic infection. It has a recurrence rate of about $12-14 \% .^{13,15}$

\section{CONCLUSION}

Dentigerous cyst involving maxillary sinus with ectopic third molar is rare entity. At initial stage dentigerous cyst involving maxillary sinus present asymptomatic unless it gets infected. Use of orthopantomograph and CT scan can help 


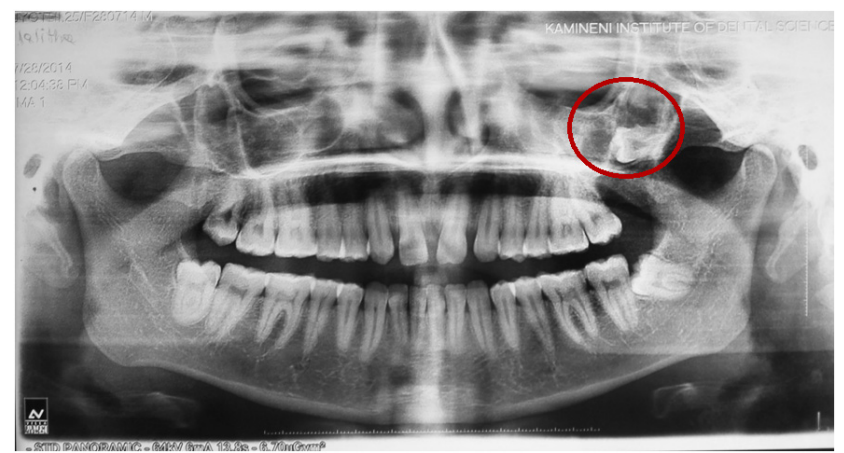

Figure 1: Pre-operative panaromic radiograph showing impacted third molar in the left maxillary sinus.

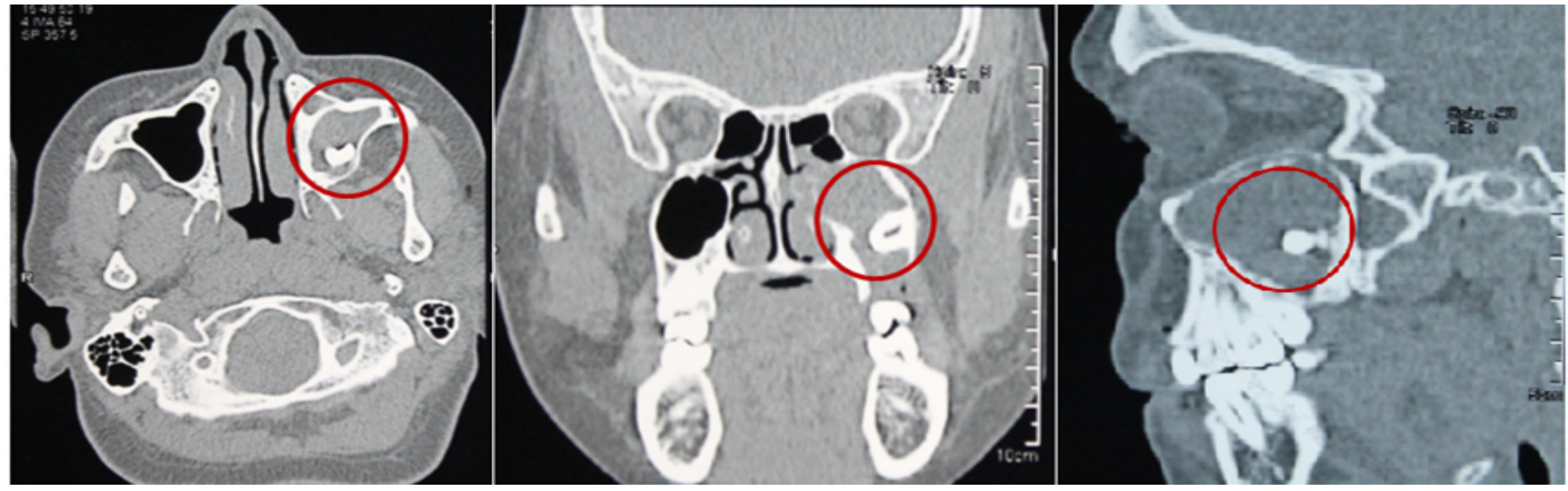

Figure 2: Axial, coronal and sagittal CT image showing impacted third molar in the posterolateral aspect of left maxillary sinus

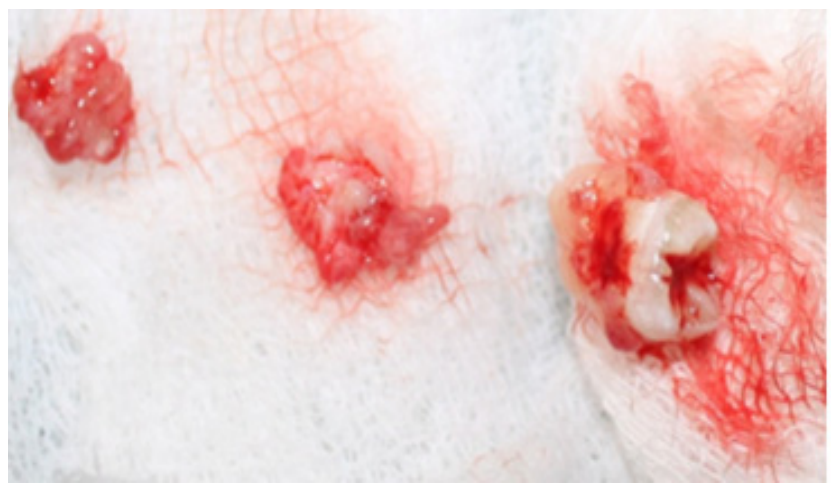

Figure 3: Excisional biopsy specimen showing cystic lining with tooth

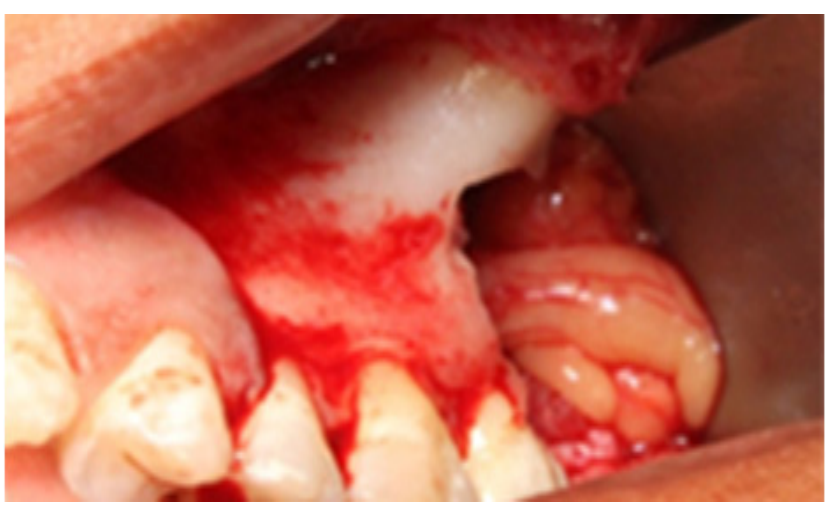

Figure 4: Buccal fat pad placed into the bony window

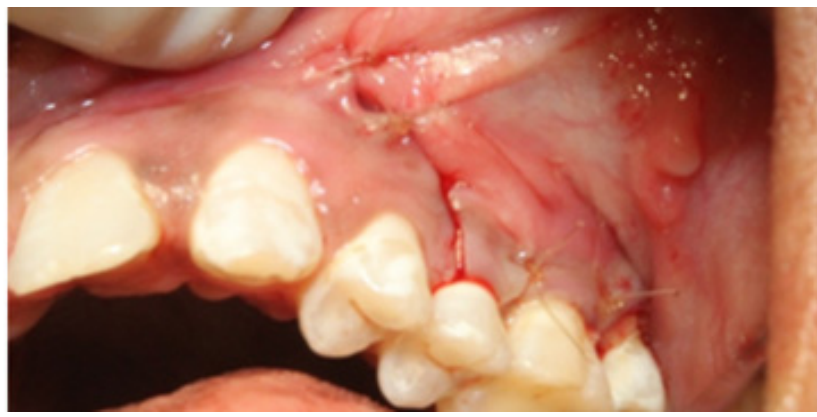

Figure 5: Intra oral picture showing closure of the defect 
diagnosing the lesion and appropriate treatment planning. Treatment of such lesions by enucleation along with removal of tooth involved has to be indicated. Untreated cases of dentigerous cyst can undergo malignant transformation. Closure with buccal fat pad after enucleation of dentigerous cyst with third molar found to be a superior.

\section{References}

1. Prasad TS, Sujatha G, Niazi TM, Rajesh P. Dentigerous cyst associated with an ectopic third molar in the maxillary sinus: a rare entity. IJ DR 2007;18(3):141.

2. Goh YH. Ectopic eruption of maxillary molar tooth-an unusual cause of recurrent sinusitis. Singapore Med J 2001; $42(2): 80-1$

3. Shafer WG, MK Levy BM. A textbook of oral pathology. 1983: 260.

4. NevilleBW, Damm DD, Allen CM, BouquotJ E. Odontogenic cysts and tumors. Oral Maxillofacial Path 2002; 589-642.

5. Kusukawa J , Irie K, Morimatsu M, Koyanagi S, Kameyama T. Dentigerous cyst associated with a deciduous tooth: A case report. Oral Surg Oral Med Oral Path 1992;73(4):4158.

6. Bodner L, Tovi F, Bar-Ziv J . Teeth in the maxillary sinusimaging and management. J Laryngology Otology 1997;111(09):820-4.
7. Di Pasquale $P$, Shermetaro $C$. Endoscopic removal of a dentigerous cyst producing unilateral maxillary sinus opacification on computed tomography. Ear Nose Throat J 2006;85(11):747-9.

8. Buyukkurt MC, Tozoglu S, Aras MH, Yolcu U. Ectopic eruption of a maxillary third molar tooth in the maxillary sinus: a case report. J Contemp Dent Pract 2005;6(3):10410.

9. Bhaskar SN. Synopsis of oral pathology. 7th ed. CBS Publisher: 1986: 228-37.

10. Laskin DM. Oral surgery. 1st ed. Cr. Mosby: 1996: 459.

11. Baumann A, Ewers R. Application of the buccal fat pad in oral reconstruction. J Oral Maxillofacial Surg 2000;58(4):389-92.

12. Szerlip L. Displaced third molar with dentigerous cyst-an unusual case. J Oral Surg(American Dental Association: 1965) 1978;36(7):551-2.

13. Mohan S, Kankariya H, Harjani B, Sharma H. Ectopic third molar in the maxillary sinus. National J Maxillofacial Surgery 2011;2(2):222.

14. Kasat VO, Karjodkar FR, Laddha RS. Dentigerous cyst associated with an ectopicthird molar in the maxillary sinus: A case report and review of literature. Contemporary Clin Dent 2012;3(3):373.

15. Yasuoka $\mathrm{T}$, Y onemoto $\mathrm{K}, \mathrm{K}$ ato $\mathrm{Y}$, Tatematsu N. Squamous cell carcinoma arising in a dentigerous cyst. J Oral Maxillofacial Surg 2000;58(8):900-5.

\section{Gain quick access to our journal online View our journal at www.nacd.in}

